\title{
West Haven Hepatic Encephalopathy Grade Clinical Classification
}

National Cancer Institute

\section{Source}

National Cancer Institute. West Haven Hepatic Encephalopathy Grade Clinical

Classification. NCI Thesaurus. Code C124709.

A standardized rating scale developed by Blei and Cordoba in 2001, which is a

classification system used to describe the severity of hepatic encephalopathy based on the level of mental status and intellectual function. This instrument has 4 grades. 